\title{
Peak Expiratory Flow
}

National Cancer Institute

\section{Source}

National Cancer Institute. Peak Expiratory Flow. NCI Thesaurus. Code C41372.

The maximum rate of gas flow, beginning at the point of peak inspiratory capacity, that can be sustained during forced exhalation for a defined period of time. This test is most often used in combination with other studies of lung function to diagnose and monitor obstructive and restrictive lung disease(s). 